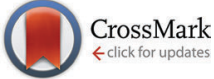

Cite this: Phys. Chem. Chem. Phys., 2015, 17, 3024

\title{
Remarkable improvement in microwave absorption by cloaking a micro-scaled tetrapod hollow with helical carbon nanofibers $\dagger$
}

\author{
Xian Jian, ${ }^{\text {ab }}$ Xiangnan Chen, ${ }^{a}$ Zuowan Zhou, ${ }^{a}$ Gang Li, ${ }^{c}$ Man Jiang, ${ }^{a}$ Xiaoling Xu, ${ }^{a}$ \\ Jun Lu, ${ }^{a}$ Qiming Li, ${ }^{d}$ Yong Wang, ${ }^{a}$ Jihua Gou ${ }^{e}$ and David Hui ${ }^{f}$
}

\begin{abstract}
Helical nanofibers are prepared through in situ growth on the surface of a tetrapod-shaped ZnO whisker ( $\mathrm{T}-\mathrm{ZnO})$, by employing a precursor decomposition method then adding substrate. After heat treatment at $900{ }^{\circ} \mathrm{C}$ under argon, this new composite material, named helical nanofiber-T-ZnO, undergoes a significant change in morphology and structure. The $\mathrm{T}-\mathrm{ZnO}$ transforms from a solid tetrapod $\mathrm{ZnO}$ to a micro-scaled tetrapod hollow carbon film by reduction of the organic fiber at $900{ }^{\circ} \mathrm{C}$. Besides, helical carbon nanofibers, generated from the carbonization of helical nanofibers, maintain the helical morphology. Interestingly, HCNFs with the T-hollow exhibit remarkable improvement in electromagnetic wave loss compared with the pure helical nanofibers. The enhanced loss ability may arise from the efficient dielectric friction, interface effect in

the complex nanostructures and the micro-scaled tetrapod-hollow structure.
\end{abstract}

Received 23rd October 2014 Accepted 27th November 2014

DOI: $10.1039 / \mathrm{c} 4 \mathrm{cp} 04849 \mathrm{k}$

www.rsc.org/pccp

\section{Introduction}

Advances in catalysis are critical to modern nanotechnology. ${ }^{1,2}$ At present, nanocatalysts have shown promising application potential in many fields. They can be used in a wide variety of applications such as synthesis, ${ }^{3}$ electronics ${ }^{4,5}$ and medicine. ${ }^{6}$ The use of carrier-supported catalysts is a simple and effective method to enhance or alter the catalytic performance., ${ }^{2,7-10}$ Combined with appropriate interaction with the substrate, catalysts with designed functions can be realized. For example, both pure $\mathrm{Cu}$ and $\mathrm{ZnO}$ don't possess good catalytic properties during methanol synthesis using gas mixtures of $\mathrm{H}_{2}-\mathrm{CO}_{2}-\mathrm{CO}$. However, $\mathrm{Cu} / \mathrm{ZnO} / \mathrm{Al}_{2} \mathrm{O}_{3}$ is a high-performance industrial catalyst

\footnotetext{
${ }^{a}$ Key Laboratory of Advanced Technologies of Materials (Ministry of Education), School of Materials Science and Engineering, Southwest Jiaotong University, Chengdu 610031, China. E-mail: zwzhou@at-c.net; Fax: +86 028-87600454; Tel: +86 028-87600454

${ }^{b}$ School of Energy Science and Engineering, University of Electronic Science and Technology of China, Chengdu, Sichuan 611731, China.

E-mail: jianxian20033835@163.com, jianxian@uestc.edu.cn

${ }^{c}$ Research Center for Eco-Environmental Sciences, Chinese Academy of Sciences, Beijing 100085, China. E-mail: gangli@rcees.ac.cn

${ }^{d}$ Shanghai Institute of Applied Physics, Key Laboratory of Nuclear Radiation and Nuclear Energy Technology Chinese Academy of Sciences, Shanghai 201800, China ${ }^{e}$ Department of Mechanical, Materials and Aerospace Engineering, University of Central Florida, Orlando, FL 32816, USA

${ }^{f}$ Department of Mechanical Engineering, University of New Orleans, New Orleans, LA 70148, USA

$\dagger$ Electronic supplementary information (ESI) available. See DOI: 10.1039/ c4cp $04849 \mathrm{k}$
}

due to the existence of active sites consisting of $\mathrm{Cu}$ decorated with $\mathrm{Zn}$ atoms. ${ }^{11}$ Besides, the introduction of a substrate helps to form catalysts with high uniformity and selectivity. Ren et al. reported helical carbon nanofibers (HCNFs) synthesized by the catalytic decomposition of acetylene using supported copper catalysts including $\mathrm{Cu} / \mathrm{SiO}_{2}, \mathrm{Cu} / \mathrm{TiO}_{2}, \mathrm{Cu} / \mathrm{Al}_{2} \mathrm{O}_{3}$ and $\mathrm{Cu} / \mathrm{MgO}$ particles. ${ }^{12}$ Ren et al. also found that the content of HCNFs strongly depended on the type of catalytic supports and ratio of $\mathrm{Cu} /$ support. $^{12}$ At present, preparing helical nanofibers, ${ }^{13-16}$ such as HCNFs, using novel catalyst has attracted great interest from researchers in the field of synthesis and related nanomaterials. ${ }^{17-19}$ However, few works in the literature are concerned with the interaction between the $\mathrm{ZnO}$ matrix and $\mathrm{Cu}$ nanocrystals in helical fiber synthesis, which may have a great influence on the catalysts' properties.

In the field of microwave absorption, carbon-based composite materials have some advantages compared with traditional ferrite materials, such as low density and high values of complex permittivity, which may improve the microwave absorption properties and electromagnetic interference shielding effect. ${ }^{20}$ In fact, the microwave absorption properties are influenced by the interfacial interactions of novel structures. $\mathrm{Bi}$ et al. reported that the decoration of bowl-like hollow $\mathrm{Fe}_{3} \mathrm{O}_{4}$ spheres on both sides of the r-GO nanosheets enhanced greatly the dielectric loss of the materials, resulting in a wider absorption band and a larger reflection loss in the frequency range of 2-18 GHz. ${ }^{21}$ Pores in the micro-spheres also increase specimen microwave loss due to spin-transfer effects. ${ }^{22}$ So, it is valuable to design novel multi-scale structures or those with different 
morphologies such as grain size, porosity and intra- or intergranular pores, etc.

A previous study found that coordination polymerization of acetylene occurs on the surface of the Cu nanocrystal, ${ }^{23}$ and the helical or straight carbon fiber can be prepared selectively using a gas-induced technique. ${ }^{24,25}$ Here, we find that the interaction between $\mathrm{Cu}$ and the $\mathrm{ZnO}$ crystal is fairly strong and has substantial impact during the catalysis of acetylene by copper. By adjusting the molar concentration of copper, we can obtain selectively a corn-like $\mathrm{ZnO}$ or helical fiber-T-ZnO. In addition, a novel multiple structure named as helical carbon fibers with a tetrapod-hollow feature (mentioned as "T-hollow" hereafter) are prepared from the carbonization of helical fiber-T-ZnO material after thermal treatment. Compared with high-purity helical nanofibers, T-hollow exhibits excellent microwave absorption properties.

\section{Results and discussion}

\section{Preparation of helical nanofibers-T-ZnO}

The process of preparing helical nanofibers-T-ZnO is depicted in Fig. 1. T-ZnO whiskers with a diameter of $20 \mu \mathrm{m}$ were used as a catalyst substrate. The obtained supported catalyst, namely copper tartrate/T-ZnO, is used for the growth of helical nanofibers according to our earlier reported gas-induced method under $\mathrm{C}_{2} \mathrm{H}_{2}$ at $271{ }^{\circ} \mathrm{C} .{ }^{25}$

The amount of catalyst precursors loaded on the $\mathrm{T}-\mathrm{ZnO}$ substrate affects significantly the size of the $\mathrm{Cu}$ nanocrystals and the degree of their agglomeration. Fig. 2 shows electron microscopic images of copper tartrate-T-ZnO (Fig. 2a and b) and $\mathrm{Cu}-\mathrm{T}-\mathrm{ZnO}$ (Fig. 2c and $\mathrm{d}$ ) with a $\mathrm{Cu}$ concentration of $0.6 \mathrm{~mol} \%$. The SEM results show that copper tartrate adheres
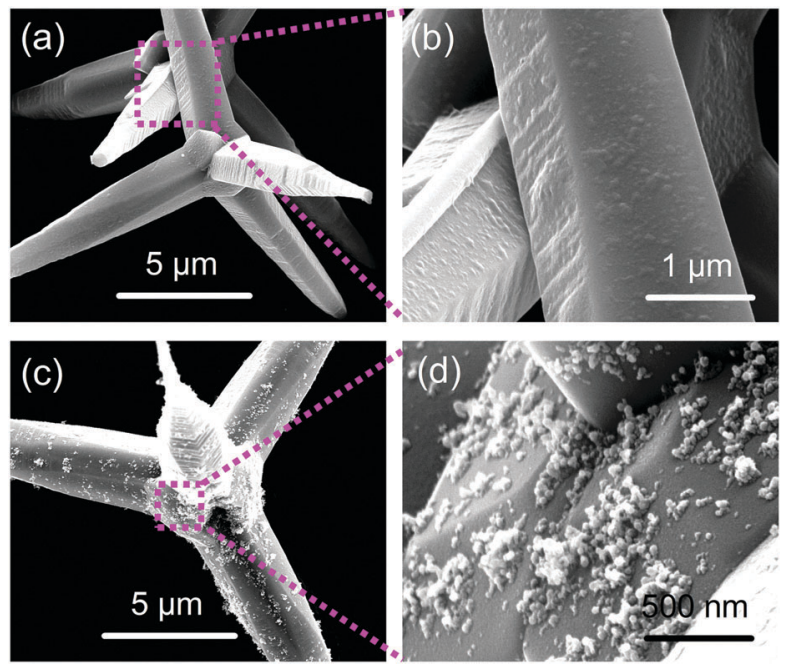

Fig. 2 SEM images of (a, b) copper tartrate-T-ZnO and (c, d) Cu-T-ZnO $(\mathrm{Cu} / \mathrm{ZnO}=0.6 \mathrm{~mol} \%)$.

uniformly to the surface of $\mathrm{T}-\mathrm{ZnO}$ and decomposes into $\mathrm{Cu}$ nanocrystals under $\mathrm{H}_{2}$ at $271{ }^{\circ} \mathrm{C}$. Driven by the minimization of their surface energy, $\mathrm{Cu}$ nanocrystals aggregate as shown in Fig. 2d. However, the small size within a certain range of the $\mathrm{Cu}$ nanocrystals facilitates the preparation of original helical nanofibers according to our previous study. ${ }^{24,25}$ Furthermore, the $\mathrm{Cu}$ nanocrystals become smaller and firmly interspersed on the surface of T-ZnO by decreasing the $\mathrm{Cu}$ constituent to $0.2-0.4 \mathrm{~mol} \%$, as shown in Fig. S1a and b (see ESI $\dagger$ ). Contrarily, the as-prepared $\mathrm{Cu}$ particles become more varied and tend to aggregate in case of increasing $\mathrm{Cu}$ content to $0.8 \mathrm{~mol} \%$ or $1.0 \mathrm{~mol} \%$ (see Fig. S1d and e, ESI $\dagger$ ). Accordingly, the size and uniformity of $\mathrm{Cu}$ particles depends strongly on the feeding molar concentration of copper tartrate.

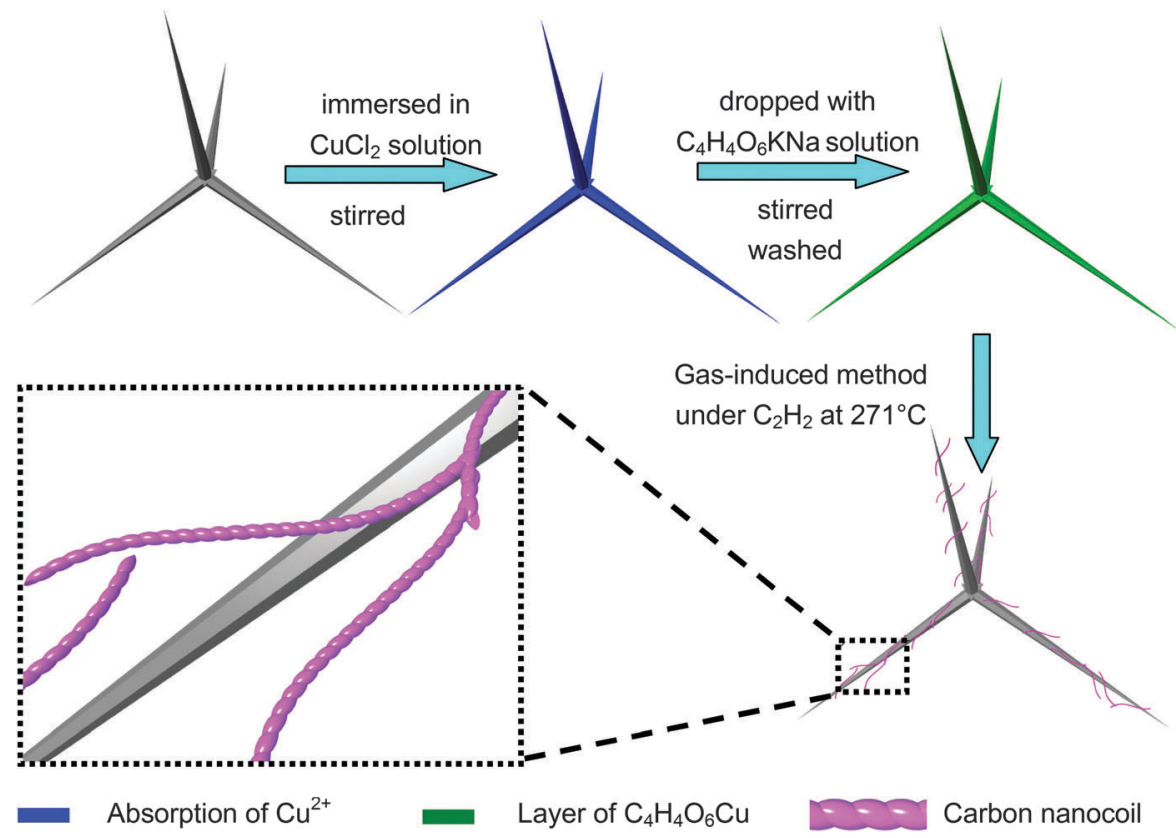

Fig. 1 Scheme for the preparation of original helical nanofibers on the surface of $\mathrm{T}-\mathrm{ZnO}$. 


\section{Structural analysis of helical nanofibers-T-ZnO}

Though copper tartrate decomposes into $\mathrm{Cu}$ nanocrystals and some gaseous reaction products above $250{ }^{\circ} \mathrm{C},{ }^{26}$ it is unclear whether these $\mathrm{Cu}$ nanocrystals remain on the surface of $\mathrm{T}-\mathrm{ZnO}$ during the decomposition process. We herein investigate the $\mathrm{Cu}-\mathrm{T}-\mathrm{ZnO}$ products by X-ray powder diffraction (XRD) and X-ray photoelectron spectroscopy (XPS). XRD patterns of the Cu-T-ZnO composites are shown in Fig. 3, together with pure T-ZnO materials as comparison. It is intriguing that no $\mathrm{Cu}$ phase appears in the obtained $\mathrm{Cu}-\mathrm{T}-\mathrm{ZnO}$ products. The XRD results are inconsistent with SEM observation (see Fig. S1, ESI $\dagger$ ), indicating that the $\mathrm{Cu}$ particles lie on the $\mathrm{T}-\mathrm{ZnO}$ surface. The reason may be that the $\mathrm{Cu}$ concentration is too low, beyond the XRD detection limit. As the $\mathrm{Cu}$ constituent increases, the diffraction peak of the $\mathrm{Cu}$ phase is detected at $43.3^{\circ}$, corresponding to $\mathrm{Cu}(111)$, as presented in Fig. S2 (ESI $\dagger$ ).

XRD and XPS analyses have been used to identify the constituent and the valence state of the samples. XPS spectra of $\mathrm{Cu}-\mathrm{T}-\mathrm{ZnO}(0.4 \mathrm{~mol} \%)$ are shown in Fig. 4 and Fig. S3 (ESI $\dagger$ ),

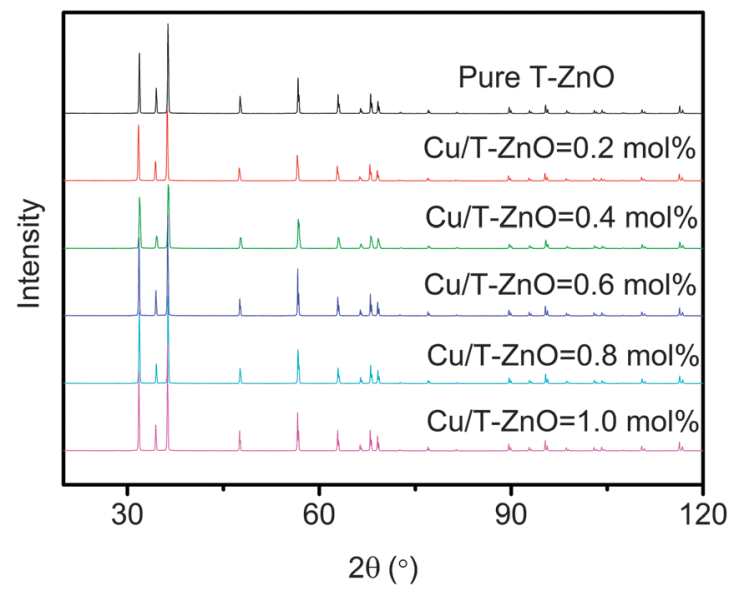

Fig. $3 \mathrm{XRD}$ patterns of pure $\mathrm{T}-\mathrm{ZnO}$ and $\mathrm{Cu}-\mathrm{T}-\mathrm{ZnO}$ at the range of $0.2-1.0 \mathrm{~mol} \%$.
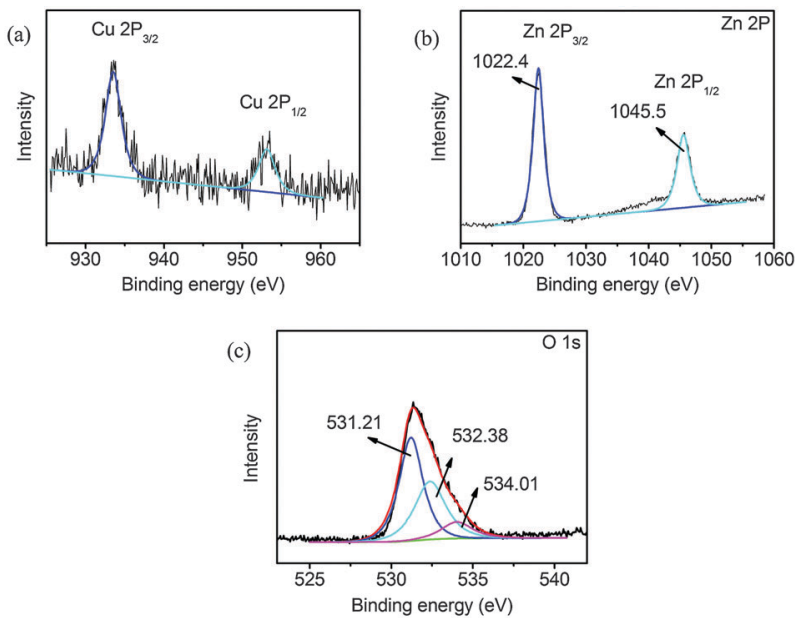

Fig. 4 XPS spectra of Cu-T-ZnO: (a) $\mathrm{Cu} 2 p$, (b) Zn 2p and (c) O 1s. which indicate that $\mathrm{Cu}, \mathrm{Zn}$ and $\mathrm{O}$ elements exist in the products. The $\mathrm{Cu} 2 \mathrm{p}_{3 / 2}$ binding energy in $\mathrm{Cu}-\mathrm{T}-\mathrm{ZnO}$ sample is $933.5 \mathrm{eV}$. The $\mathrm{Cu} 2 \mathrm{p}_{3 / 2}$ binding energies for $\mathrm{Cu},{ }^{27} \mathrm{Cu}_{2} \mathrm{O}^{28}$ and $\mathrm{CuO}^{29,30}$ are 932.6, 932.55 and $934.6 \mathrm{eV}$, respectively. The satellite peak appears in the high-resolution XPS shown in Fig. 4a, which is a typical feature of copper oxides. The nanocrystals on the surface of $\mathrm{T}-\mathrm{ZnO}$ are identified as $\mathrm{CuO}$, possibly due to the strong interaction of T-ZnO. Similarly, as shown in Fig. 4 b, we find that the binding energies for $\mathrm{Zn} 2 \mathrm{p}_{3 / 2}$ and $\mathrm{Zn} 2 \mathrm{p}_{1 / 2}$ are 1022.4 and $1045.5 \mathrm{eV}$, respectively. These values are larger than those reported by Jing et al. ${ }^{31}$ from which we can further suggest the formation of a $\mathrm{Cu}^{+}-\mathrm{O}-\mathrm{Zn}^{n+}$ hybridization structure on the surface of T-ZnO. It is possible that $\mathrm{Cu}$ is easily oxidized in air. However, CuO tends to favor the growth of straight nanofibers, which has been proposed by a previous study. ${ }^{32}$

At relatively low reaction temperatures, below $300{ }^{\circ} \mathrm{C}$, copper is an effective catalyst for the synthesis of helical nanofibers. ${ }^{25}$ Copper nanocrystals disperse well on the surfaces of T-ZnO with a copper content adjusted in the range $0.2-0.4 \mathrm{~mol} \%$. The Cu-T-ZnO composite catalyst is effective for the synthesis in situ of uniform helical nanofibers adhered to the surface of T-ZnO. However, the obtained products don't contain any fibers, but a kind of corn stick structure, as shown in Fig. S4 (ESI $\dagger$ ). This sample is named corn cob-like T-ZnO. The corn-kernel's sizes are at the range of 32$124 \mathrm{~nm}$ and 55-214 $\mathrm{nm}$ when molar ratios of $\mathrm{Cu} / \mathrm{T}-\mathrm{ZnO}$ are 0.2 $\mathrm{mol} \%$ and $0.4 \mathrm{~mol} \%$, respectively. As reported in a previous paper, $\mathrm{CuO}$ is a catalyst for straight carbon nanofibers. ${ }^{32}$ Thus, $\mathrm{CuO}$ has the ability to promote the polymerization of acetylene, forming a "corn kernel" fixed on the surface of T-ZnO.

At the other extreme, as the $\mathrm{Cu}$ constituent in the composite catalyst increases to more than $0.8 \mathrm{~mol} \%$, fibers generate around the T-ZnO particles, as shown in Fig. S5 (ESI $\dagger$ ). The fiber diameter becomes larger and their morphologies differ from each other. After coordination polymerization of $\mathrm{C}_{2} \mathrm{H}_{2}$ at $271{ }^{\circ} \mathrm{C}$ using $\mathrm{Cu} / \mathrm{T}-\mathrm{ZnO}$ catalyst, three kinds of fibers, including straight nanofibers, nano-helices and micro-helices exist among the fiber-T-ZnO samples. The formation of a mixed-type fiber is due to $\mathrm{Cu}$ particles with great diversity in terms of size and shape.

\section{Formation of helical nanofibers-T-ZnO}

Several different types of catalysts can lead to the growth of helical carbon fibers. ${ }^{33,34}$ To obtain high-purity helical nanofibers, a uniform $\mathrm{Cu}$ catalyst is essential, since the morphology of this kind of nanofiber is related to the polygonal nature of $\mathrm{Cu}$ particles. ${ }^{25,35}$ By optimizing the content of $\mathrm{Cu}$, we obtain highpurity helical nanofibers around the T-ZnO particles. Firstly, the molar ratio of $\mathrm{Cu}$ to $\mathrm{T}-\mathrm{ZnO}$ is controlled to be $\sim 0.6 \mathrm{~mol} \%$. Then, $\mathrm{Cu}$ nanocrystals are prepared from the decomposition of copper tartrate under the effect of acetylene-induction. Finally, high-purity helical nanofibers are in situ synthesized from acetylene polymerization around T-ZnO particles, as shown in Fig. 5a and b. Interestingly, a material with a novel structure is obtained from the helical nanofibers-T-ZnO composites after heat treatment at $900{ }^{\circ} \mathrm{C}$ under $\mathrm{Ar}$ for $4 \mathrm{~h}$.

The morphology of this material, named helical fiber with tetrapod-hollow, is shown in Fig. $5 \mathrm{c}$ and d. The helical structure 

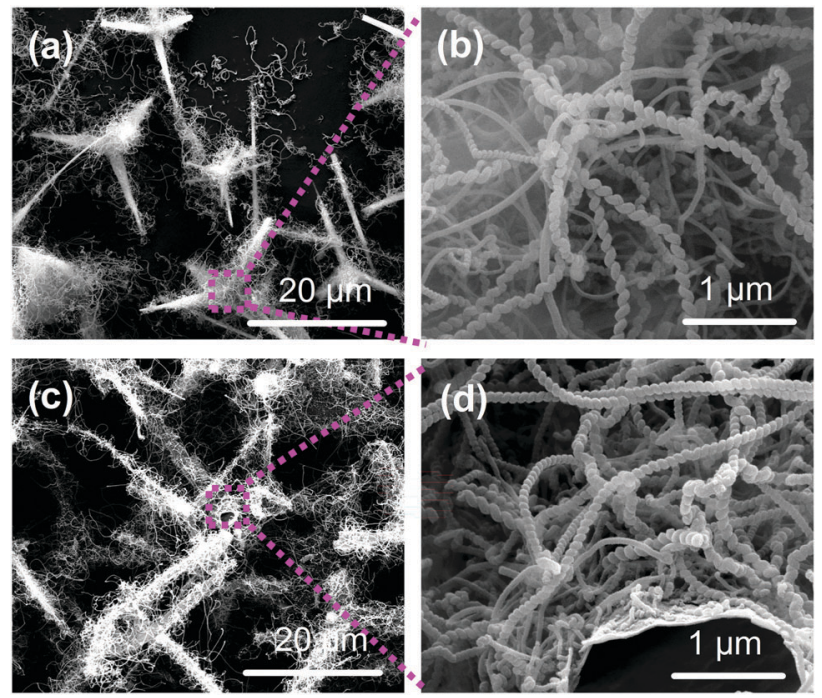

Fig. 5 SEM images of high-purity helical nanofiber-T-ZnO composites: (a, b) using $\mathrm{Cu}-\mathrm{T}-\mathrm{ZnO}(0.6 \mathrm{~mol} \%)$ as catalyst and helical fibers with the tetrapod-hollow structure; (c, d) obtained from the helical nanofiber-T-ZnO composites after heat treatment at $900{ }^{\circ} \mathrm{C}$ under $\mathrm{Ar}$ for $4 \mathrm{~h}$.

of the original helix is retained well during the carbonization process. Interestingly, the $\mathrm{T}-\mathrm{ZnO}$ crystals disappear, which brings about the tetrapod-hollow structure at the scale range of 1-3 $\mu \mathrm{m}$. Among the possible causes, we speculate that $\mathrm{ZnO}$ is reduced by $\mathrm{H}_{2}$ or $\mathrm{CO}$ released from the pyrolysis of helical fibers containing $-\mathrm{CH}=\mathrm{CH}-$ groups. ${ }^{24}$ Then, $\mathrm{T}-\mathrm{ZnO}$ is transformed from the solid semiconductor into $\mathrm{Zn}$ vapor at a high temperature of $900{ }^{\circ} \mathrm{C}$. Under the impetus of argon flow, zinc vapor discharges out of the solid sample and assembles together inside the quartz tube tail, resulting in the formation of a hollow structure. This inference is in agreement with the fact that a black buck material with a metallic luster coheres at the end of the quartz tube. EDX result also verifies the black buck containing Zn and C elements (see Fig. S6, ESI $\dagger$ ). As a result, T-hollow with the tetrapod-hollow and multi-scaled porous structures are obtained using such a heat-treatment process.

The morphology and microstructure of the samples are further analyzed by TEM, which reveals that high-purity helical nanofibers are still wrapped around the T-ZnO particles, as shown in Fig. 6a. Helical fibers of bright-dark contrast and black T-ZnO pods are observed in the magnified TEM image of Fig. $6 \mathrm{~b}$, revealing that helical fibers are amorphous and the pods are crystalline in character. For the carbonized products, a micro-sized hollow structure is observed in the TEM image at low magnification in Fig. 6c, revealing that T-ZnO has disappeared after heat-treatment. Moreover, the helical structure of this nanofiber is well maintained, as shown in Fig. 6d. T-Hollow structures are then obtained and these attain a quasi-graphite structure, from the analysis of the high-magnification TEM image in Fig. 6e. Besides, the TEM results demonstrate that wall of the "T-hollow" strucutres are amorphous carbon, as shown in Fig. S7 (ESI†). XRD patterns of the three samples, namely T-ZnO, helical fibers-T-ZnO and helical fibers with tetrapod-hollow structures are shown in Fig. S8 (ESI $\dagger$ ). For the helical fiber-T-ZnO composite, crystalline
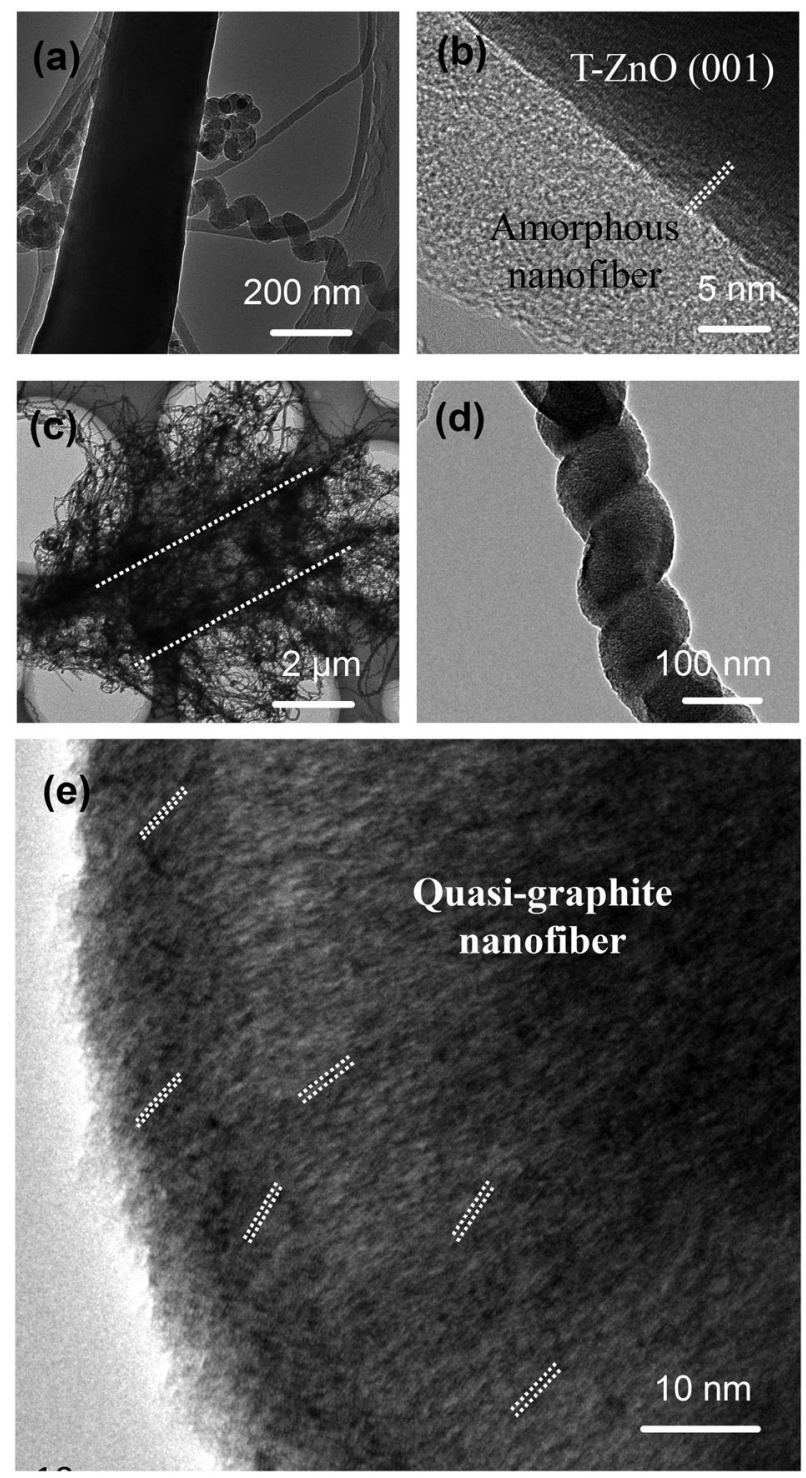

Fig. 6 TEM images of high-purity helical nanofiber-T-ZnO: $(a, b)$ using $\mathrm{Cu}-\mathrm{T}-\mathrm{ZnO}(0.6 \mathrm{~mol} \%)$ as catalyst and helical fibers with tetrapod-hollow; (c-e) obtained from the helical nanofiber-T-ZnO composites after heat treatment at $900{ }^{\circ} \mathrm{C}$ under $\mathrm{Ar}$ for $4 \mathrm{~h}$.

diffraction peaks of $\mathrm{ZnO}$ appear in the corresponding XRD patterns, which is mainly because of the amorphous structure of helical fibers and the large mass ratio of crystalline $\mathrm{ZnO}$. In addition, the XRD results of helical fibers with the tetrapodhollow structure show that both the quasi-graphite strucutre and $\mathrm{Cu}$ catalyst remain in the hollow product after heat treatment. The diffraction peaks of $\mathrm{ZnO}$ are not detected, which re-confirms strongly that T-ZnO is reduced into metallic $\mathrm{Zn}$ vapor, and the $\mathrm{Zn}$ vapor escaped from the reaction tube by the argon carrying gas, resulting in the subsequent creation of tetrapod-hollow structures.

\section{Microwave absorption properties of related helical materials}

We herein studied the electromagnetic properties of the original helical nanofibers, HCNFs and T-hollow structures across 

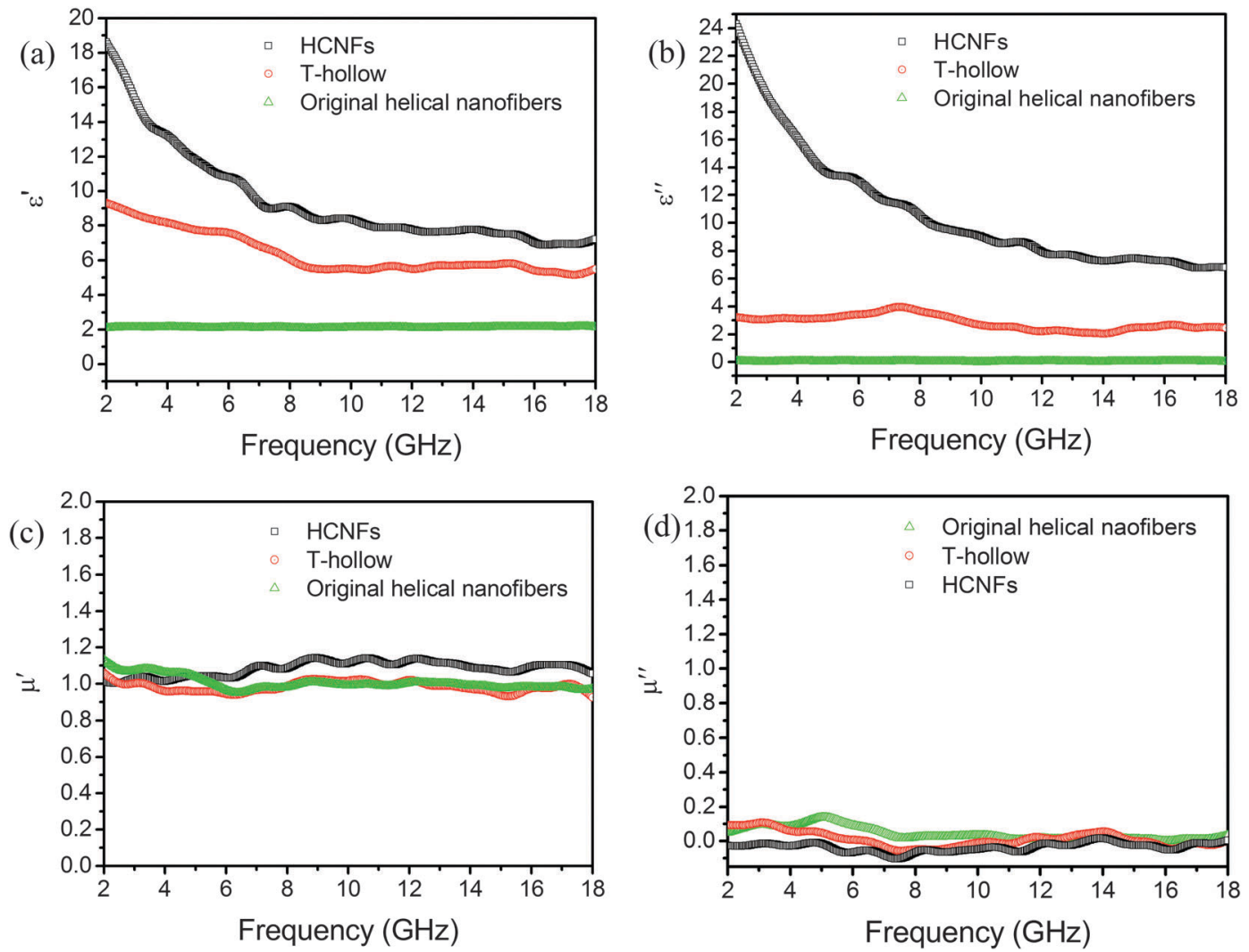

Fig. 7 Measured relative $(a, b)$ complex permittivity and $(c, d)$ complex permeability values of original helical nanofibers, helical carbon nanofibers and helical fibers with tetrapod-hollow structure. All the measured samples are uniformly mixed with the same weight of wax paraffin (sample: wax $=1: 9$ ).

the $2-18 \mathrm{GHz}$ frequency ranges. For the three kinds of helical materials, Fig. 7 shows their complex permittivity and permeability consisting of the real part $\left(\varepsilon^{\prime}, \mu^{\prime}\right)$ and imaginary part $\left(\varepsilon^{\prime \prime}, \mu^{\prime \prime}\right)$ over the $2-18 \mathrm{GHz}$ range. Both HCNFs and T-hollow have a frequency dependence of complex permittivity, while original helical nanofiber is almost constant at 2-18 GHz. The difference of dielectric characteristics between them are a consequence of the intrinsic dielectric loss of proper conductive objects. The electrical conductivities of HCNFs and T-hollow are about $10^{-1} \mathrm{~S} \mathrm{~cm}^{-1}$ measured by the four-point probe method, higher than the value $\left(\sim 10^{-9} \mathrm{~S} \mathrm{~cm}^{-1}\right)$ of the original helical nanofibers. The electronic conductivity of the microwave absorbent is key in microwave applications, and should be controlled at an optimum range of $10^{-1}-10^{2} \mathrm{~S} \mathrm{~cm}^{-1}$ for microwave penetration into the bulk absorbent. ${ }^{36}$ Due to the absence of magnetic substances the in samples, the helical materials don't exhibit any magnetic behavior, as shown in Fig. 8.

Based on the measured data of complex permittivity and permeability, the values of reflection loss (RL) of the original helical nanofiber, HCNFs and T-hollow were calculated according to the transmission line theory. Then the microwave absorption properties were estimated using the $\mathrm{RL}(\mathrm{dB})$, described as following expression. ${ }^{37}$

$$
\mathrm{RL}(\mathrm{dB})=20 \log \left|\frac{Z_{\text {in }}-1}{Z_{\text {in }}+1}\right|
$$

where $Z_{\text {in }}$ is the input characteristic impedance at the interface between the absorber and air, which can be expressed as

$$
Z_{\text {in }}=\sqrt{\frac{\mu_{\mathrm{r}}}{\varepsilon_{\mathrm{r}}}} \tanh i \frac{2 \pi f}{c} \sqrt{\mu_{\mathrm{r}} \varepsilon_{\mathrm{r}}} d
$$

where the $\mu_{\mathrm{r}}$ and $\varepsilon_{\mathrm{r}}$ are, respectively, the relative complex permittivity and permeability of absorber, $f$ is the frequency of the electromagnetic wave, $c$ is the velocity of light, and $d$ is the thickness of the absorber.

Fig. 9a shows a comparison of the calculated RL curves over the $2-18 \mathrm{GHz}$ frequency range for the sample-wax composites with a thickness of $3 \mathrm{~mm}$. It can be seen that the microwave absorption properties of the original helical nanofibers are expected mainly from dielectric loss, with RL values more than $-2.0 \mathrm{~dB}$. Compared to the pristine helical nanofibers, the RL performances toward EM waves of carbonized HCNFs are enhanced substantially. The minimum RL of HCNFs and T-hollow are -9.50 and $-15.97 \mathrm{~dB}$ at 12.3 and $17.7 \mathrm{GHz}$, respectively, as shown in Fig. 9. In addition, the frequency related to minimum RL can be modulated by increasing the thickness of absorbers, and the absorption peaks shift to lower frequency accompanied by broadening at effective absorbing frequency bands. As Qin et al. reported, materials with $\mathrm{RL}$ values of less than $-10 \mathrm{~dB}$ absorption are considered to be suitable EM wave absorbers. ${ }^{38}$ The original helical nanofibers and HCNFs are not good EM wave absorbers, but the introduction of the tetrapod-hollow into the helical fibers is an 

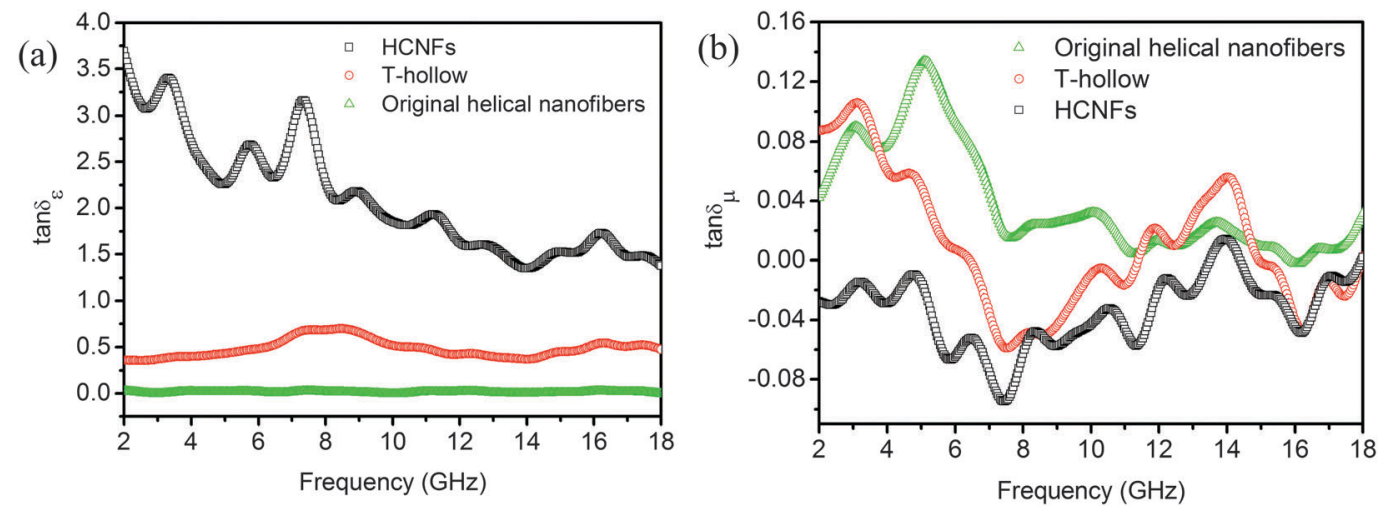

Fig. 8 Measured dielectric and magnetic loss of original helical nanofibers, HCNFs and T-hollow.

(a)

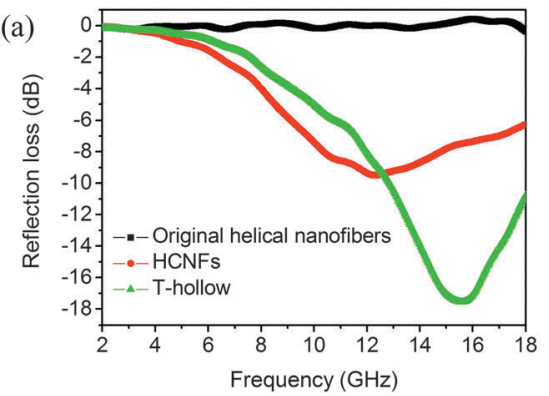

(c)

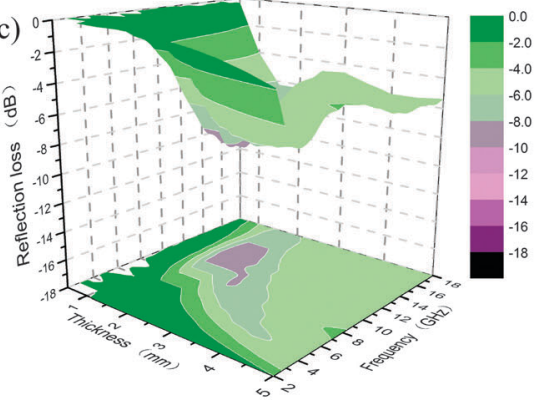

(b)

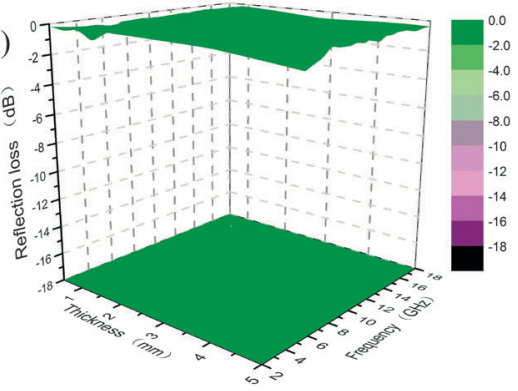

(d)

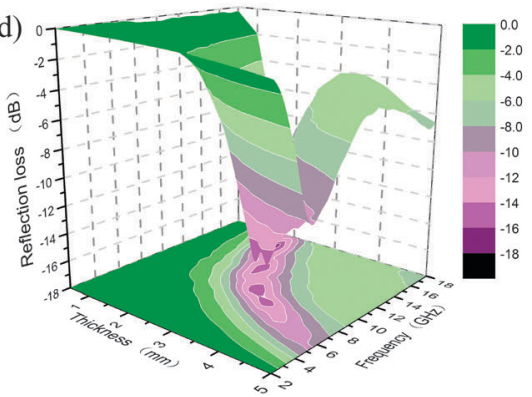

Fig. 9 (a) Microwave RL curves of the samples-wax composites with a thickness of $3 \mathrm{~mm}$ in the frequency range of 2-18 GHz, and simulated curves of electromagnetic wave loss of (b) original helical nanofiber, (c) carbon nanofiber and (d) helical fiber with the tetrapod-hollow structure (namely T-hollow).

effective way for compromising the electromagnetic wave loss. Besides, the composite method is another effective way to improve microwave absorption properties. ${ }^{39}$ The combination of the two approaches might be a potential researching design in the field of EM wave absorbers.

In addition, compared with the original helical nanofiber and HCNFs, we have studied the RL performance of straight fibers including straight original nanofibers and straight carbon fibers. For straight original fibers without any treatment, the RL values are greater than $-2.0 \mathrm{~dB}$, which is similar to the original helical fibers, exhibiting poor behavior for electromagnetic loss. Owing to their chemical structures, both helical and straight original nanofibers are insulators with electrical conductivities of about $10^{-9} \mathrm{~S} \mathrm{~cm}^{-1}$, which goes beyond the suitable range of $10^{-1}-10^{2} \mathrm{~S} \mathrm{~cm}^{-1} \cdot{ }^{36}$ Moreover, one can find that the RL performance of the carbonized straight fibers is improved and the RL values increase significantly compared to the original straight nanofibers, as shown in Fig. 10. This confirms that the carbonization process is effective for actualizing impedance matching by adjusting the electrical conductivity. Besides, both helical and straight carbon nanofibers represent a contiguous level of electromagnetic loss, suggesting that the helical structure cannot improve the electromagnetic wave loss either.

In the frequency of 2-18 GHz, HCNFs had only dielectric loss and the reflection loss values were higher than $-10 \mathrm{~dB}$, while the original helical fibers exhibited neither dielectric loss nor magnetic loss due to the low electrical conductivity. Interestingly, HCNFs with T-hollow exhibited remarkable improvement in electromagnetic wave loss compared with the pure helical nanofibers. Possible reasons for their excellent absorbing properties are as follows. (a) A factor responsible for this improvement was identified as an improved impedance match 

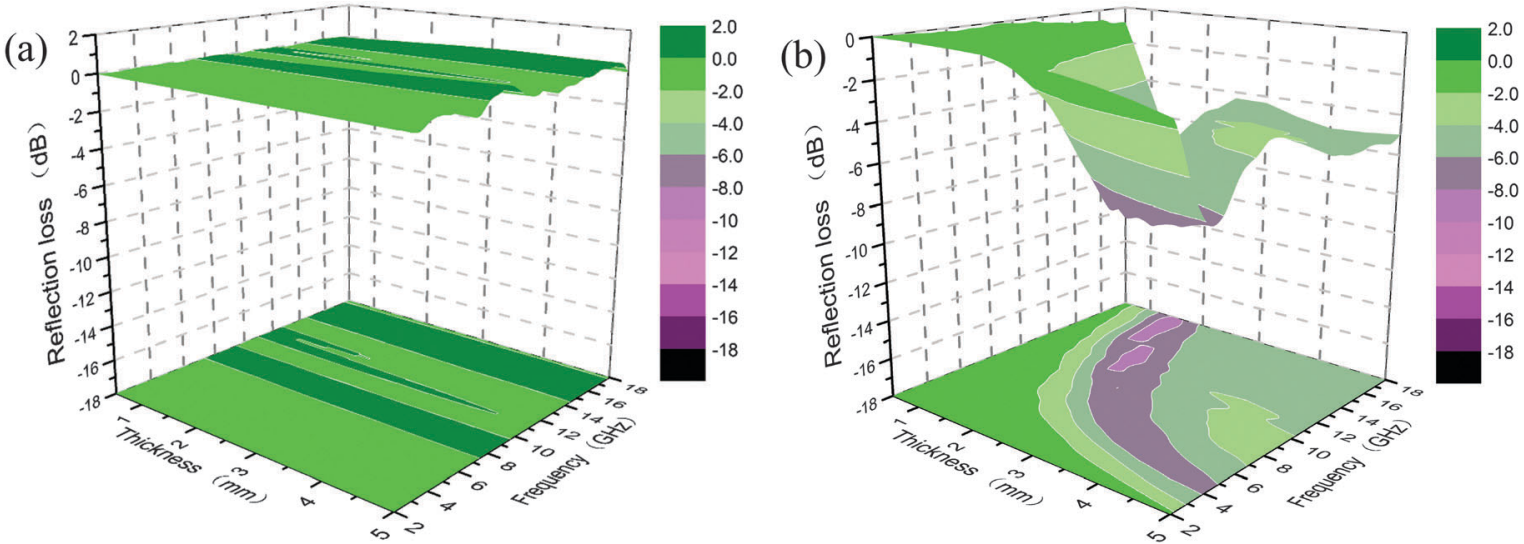

Fig. 10 Simulated curves of electromagnetic wave loss of straight original nanofibers and straight carbon fibers.

with the increase of conductivity after the carbonization process. (b) Another factor is that more energy may be dissipated due to the hollow structure; in this case spin-transfer effects may exist due to the interlayer exchange coupling. ${ }^{22}$ (c) HCNFs around the hollow structure are composed of many small graphene sheets or carbon clusters, such as amorphous carbon nanotubes, which exhibit the features of short-range order and long-range disorder. These special features favor higher performance of electromagnetic wave absorbing properties. ${ }^{40}$ (d) The enhanced loss ability might arise from the efficient dielectric friction and interface resonance in the microscaled tetrapod-hollow structures. It can be expected that the T-hollow structure, with suitable electrical conductivity and micro-and/or nanoscale structures of cavities besides chirality from the helix, plays a unique role in this new kind of structures.

\section{Experimental}

\section{Materials}

T-ZnO were obtained from the oxidation reaction of metallic zinc by the gas expanding method, as in our earlier study. ${ }^{41}$ Metallic zinc in the forms of pellets or sheets (industrial-grade purity) was burned into $\mathrm{T}$-ZnO particles at $500-800{ }^{\circ} \mathrm{C}$, keeping the gate of the furnace closed without special sealing during the whisker-generation process. A white, fluffy product was obtained, with a yield of over $95 \%$ whiskers. All the chemicals including acetylene $\left(\mathrm{C}_{2} \mathrm{H}_{2}\right)$, copper dichloride $\left(\mathrm{CuCl}_{2}\right)$ and potassium sodium tartrate $\left(\mathrm{C}_{4} \mathrm{O}_{6} \mathrm{H}_{4} \mathrm{KNa}\right)$ were purchased from commercial sources at analytical grade and were used as-received without further purification. All experiments were carried out using deionized water.

\section{Preparation of helical fibers-T-ZnO and T-hollow carbon}

The T-ZnO whiskers decorated with copper tartrate were prepared by the precipitation method using copper chloride and sodium potassium tartrate both at a concentration of $0.1 \mathrm{~mol} \mathrm{~L}^{-1}(\mathrm{M})$. The mole ratio of $\mathrm{Cu}$ to $\mathrm{ZnO}$ was adjusted in the range of $0.2-1.0 \mathrm{~mol} \%$. T-ZnO particles were loaded with $\mathrm{Cu}^{2+}$ ions after being immersed in $\mathrm{CuCl}_{2}$ solution under magnetic stirring for $30 \mathrm{~min}$. Then,
$\mathrm{C}_{4} \mathrm{H}_{4} \mathrm{O}_{6} \mathrm{KNa}$ solution was dropped into a T-ZnO suspension with stirring to form copper tartrate on the surface of T-ZnO. The obtained supported catalyst, namely copper tartrate/T-ZnO, was used for the growth of helical nanofibers according to our earlier reported gas-induced method under $\mathrm{C}_{2} \mathrm{H}_{2}$ at $271{ }^{\circ} \mathrm{C} .{ }^{25}$ Firstly, copper tartrate decomposed into $\mathrm{Cu}$ nanocrystals. After that, the helical nanofibers were in situ synthesized around the T-ZnO whiskers using the catalytic chemical vapor deposition (CCVD) method. The substrate decorated with copper tartrate was placed in the quartz tube of a chemical vapor deposition horizontal furnace. $\mathrm{Ar}$ and $\mathrm{C}_{2} \mathrm{H}_{2}$ gases were used for the exhaustion of air in the tube and the synthesis of helical nanofibers, respectively. For the synthesis of high-purity helical nanofibers, $\mathrm{C}_{2} \mathrm{H}_{2}$ gas was introduced into the quartz tube at $271{ }^{\circ} \mathrm{C}$ and $60 \mathrm{~mL} \mathrm{~min}{ }^{-1}$ for 60 min under catalytic gas-induced formation of copper nanocrystals, keeping the setup closed without cooling. After heattreatment under Ar at $900{ }^{\circ} \mathrm{C}, \mathrm{HCNFs}$ with the tetrapod hollow (T-hollow) structure were prepared from the helical nanofiberT-ZnO whiskers.

\section{Characterization}

Helical nanofiber-T-ZnO whiskers were characterized using a field emission scanning electron microscope (FE-SEM, Fei, Inspect-F) with an accelerating voltage of $20.0 \mathrm{kV}$ and transmission electron microscopy (Fei-F200) at an accelerating voltage of $200 \mathrm{kV}$, an X-ray diffraction spectrometer (XRD, Panalytical X'Pert PRO diffractometer with Ni-filtered, the Netherlands) and a digital four-point probe system (SZ-82) at room temperature. For the evaluation of the microwave absorption properties of original helical nanofibers, helical nanofibers-T-ZnO and HCNFs with the T-hollow structure, their mixtures with paraffin were pressed into toroidal shaped samples of $7.0 \mathrm{~mm}$ outer diameter and $3.4 \mathrm{~mm}$ inner diameter, respectively. The electromagnetic parameters of the samples with $10 \mathrm{wt} \%$ helical materials were measured at $2-18 \mathrm{GHz}$ with an AV3618 network analyzer. The reflection losses $R(\mathrm{~dB})$ of the helical material composites were calculated according to the transmission line theory, using the measured data of relative complex permeability and permittivity. 


\section{Conclusions}

In the frequency range of 2-18 GHz, HCNFs had only dielectric loss and the reflection loss values were higher than $-10 \mathrm{~dB}$, while the original helical fibers exhibited neither dielectric loss nor magnetic loss due to the low electrical conductivity. Interestingly, HCNFs with the T-hollow structure exhibited remarkable improvement in electromagnetic wave loss compared with the pure helical nanofibers. The enhanced loss ability might arise from an improved impedance match, the efficient dielectric friction and interfacial resonance in the complex nanostructures and the micro-scaled tetrapod-hollow structures. It can be expected that the T-hollow structure with suitable electrical conductivity and a micro-and/or nanoscale cavity structure, besides chirality from the helix, plays a unique role in the design of new functional materials.

\section{Acknowledgements}

This work was supported financially by the Open Foundation of the State Key Laboratory of Electronic Thin Films and Integrated Devices (KFJJ201411), National Natural Science Foundation of China (No. 51173148, 51302230 and 51402040) the Special Research Fund for Doctoral Program of Higher Education (No. 20060613004), the NBRP (Grant No. 2011CB606200), the Scientific and Technological Planning Projects of Sichuan Province (Nos. 2013RZ0036, 2014GZ0089, 2014PTZ0005), and the Fundamental Research Funds for the Central Universities (No. 2010XS31 and No. SWJTU11ZT10). We would like to express our appreciation for the helpful comments of Dr Yong Qin at the Chinese Academy of Science and Dr Weidong He at UESTC.

\section{References}

1 L. Zhang, J. Zhao, J. Zheng, L. Li and Z. Zhu, Sens. Actuators, $B, 2011,158,144-150$.

2 S. Li, K. Yu, Y. Wang, Z. Zhang, C. Song, H. Yin, Q. Ren and Z. Zhu, CrystEngComm, 2013, 15, 1753-1761.

3 R. Paul, A. A. Voevodin, D. Zemlyanov, A. K. Roy and T. S. Fisher, Adv. Funct. Mater., 2012, 22, 3682-3690.

4 C. Yan, W. Xi, W. Si, J. Deng and O. G. Schmidt, Adv. Mater., 2013, 25, 539-544.

5 G. Hu, F. Nitze, T. Sharifi, H. R. Barzegar and T. Wagberg, J. Mater. Chem., 2012, 22, 8541-8548.

6 C.-L. Zhu, M.-L. Zhang, Y.-J. Qiao, G. Xiao, F. Zhang and Y.-J. Chen, J. Phys. Chem. C, 2010, 114, 16229-16235.

7 X. F. Zhang, X. L. Dong, H. Huang, Y. Y. Liu, W. N. Wang, X. G. Zhu, B. Lv, J. P. Lei and C. G. Lee, Appl. Phys. Lett., 2006, 89, 053115.

8 E. Martono, M. P. Hyman and J. M. Vohs, Phys. Chem. Chem. Phys., 2011, 13, 9880-9886.

9 W. Cai, N. Homs and P. Ramirez de la Piscina, Green Chem., 2012, 14, 1035-1043.

10 X. Zhou, J. Qu, F. Xu, J. Hu, J. S. Foord, Z. Zeng, X. Hong and S. C. Edman Tsang, Chem. Commun., 2013, 49, 1747-1749.

11 Q. Song, K.-z. Li, H.-l. Li, H.-j. Li and C. Ren, Carbon, 2012, 50, 3949-3952.
12 X. Ren, H. Zhang and Z. Cui, Mater. Res. Bull., 2007, 42, 2202-2210.

13 B. Adhikari, J. Nanda and A. Banerjee, Soft Matter, 2011, 7, 8913-8922.

14 E. Busseron, Y. Ruff, E. Moulin and N. Giuseppone, Nanoscale, 2013, 5, 7098-7140.

15 S. I. Stupp, R. H. Zha, L. C. Palmer, H. Cui and R. Bitton, Faraday Discuss., 2013, 166, 9-30.

16 D. Mandal, A. Nasrolahi Shirazi and K. Parang, Org. Biomol. Chem., 2014, 12, 3544, DOI: 10.1039/C4OB00447G.

17 X. Qi, Q. Ding, W. Zhong, C.-T. Au and Y. Du, Carbon, 2013, 56, 383-385.

18 A. Shaikjee and N. J. Coville, J. Adv. Res., 2012, 3, 195-223.

19 F. Nitze, M. Mazurkiewicz, A. Malolepszy, A. Mikolajczuk, P. Kędzierzawski, C.-W. Tai, G. Hu, K. J. Kurzydłowski, L. Stobinski, A. Borodzinski and T. Wågberg, Electrochim. Acta, 2012, 63, 323-328.

20 J. Zhou, J. He, G. Li, T. Wang, D. Sun, X. Ding, J. Zhao and S. Wu, J. Phys. Chem. C, 2010, 114, 7611-7617.

21 H.-L. Xu, H. Bi and R.-B. Yang, J. Appl. Phys., 2012, 111, 07A522.

22 P. Grünberg, D. E. Bürgler, H. Dassow, A. D. Rata and C. M. Schneider, Acta Mater., 2007, 55, 1171-1182.

23 Y. Qin, H. Li, Z. Zhang and Z. Cui, Org. Lett., 2002, 4, 3123-3125. 24 X. Jian, M. Jiang, Z. Zhou, M. Yang, J. Lu, S. Hu, Y. Wang and D. Hui, Carbon, 2010, 48, 4535-4541.

25 X. Jian, M. Jiang, Z. Zhou, Q. Zeng, J. Lu, D. Wang, J. Zhu, J. Gou, Y. Wang, D. Hui and M. Yang, ACS Nano, 2012, 6, 8611-8619.

26 R. L. Schmid and J. Felsche, Thermochim. Acta, 1982, 59, 105-114.

27 P. E. Laibinis and G. M. Whitesides, J. Am. Chem. Soc., 1992, 114, 9022-9028.

28 M. Yang and J.-J. Zhu, J. Cryst. Growth, 2003, 256, 134-138. 29 S. Velu, K. Suzuki, C. S. Gopinath, H. Yoshida and T. Hattori, Phys. Chem. Chem. Phys., 2002, 4, 1990-1999.

30 N. Pasha, N. Lingaiah, P. S. Reddy and P. S. S. Prasad, Catal. Lett., 2009, 127, 101-106.

31 L. Jing, Z. Xu, X. Sun, J. Shang and W. Cai, Appl. Surf. Sci., 2001, 180, 308-314.

32 H. Zhang, X. Ren and Z. Cui, J. Cryst. Growth, 2007, 304, 206-210.

33 N. Tang, J. Wen, Y. Zhang, F. Liu, K. Lin and Y. Du, ACS Nano, 2010, 4, 241-250.

34 F. Nitze, E. Abou-Hamad and T. Wågberg, Carbon, 2011, 49, 1101-1107.

35 G. Wang, G. Ran, G. Wan, P. Yang, Z. Gao, S. Lin, C. Fu and Y. Qin, ACS Nano, 2014, 8, 5330-5338.

36 X. Zhang and S. K. Manohar, Chem. Commun., 2006, 2477-2479. 37 X. F. Zhang, H. Huang and X. L. Dong, J. Phys. Chem. C, 2013, 117, 8563-8569.

38 G. Wang, Z. Gao, S. Tang, C. Chen, F. Duan, S. Zhao, S. Lin, Y. Feng, L. Zhou and Y. Qin, ACS Nano, 2012, 6, 11009-11017.

39 L. Liu, P. He, K. Zhou and T. Chen, AIP Adv., 2013, 3, 082112.

40 T. Zhao, C. Hou, H. Zhang, R. Zhu, S. She, J. Wang, T. Li, Z. Liu and B. Wei, Sci. Rep., 2014, 4, 5619, DOI: 10.1038/ srep05619.

41 Z. Zhou, H. Deng, J. Yi and S. Liu, Mater. Res. Bull., 1999, 34, 1563-1567. 